\title{
Methods for simulating measured field responses for long-term performance of mine waste cover systems
}

\author{
R.E. Shurniak O'Kane Consultants Pty Ltd, Australia \\ M. O'Kane O'Kane Consultants Pty Ltd, Australia
}

\begin{abstract}
Mine waste cover systems are typically a key component of mine closure plans. For this reason, and because cover systems generally encompass a large component of mine closure costs, it is critical that an acceptable level of risk in determining long-term cover system performance is achieved. Numerical simulations using computers are the most common tool used to evaluate the long-term water balance of mine waste cover systems. However, the accuracy of such simulations is dependent on the quality of data available to determine model inputs. The preferred method for ensuring the most representative model inputs are used is to simulate past performance of the cover using data generated from field performance monitoring, referred to as a field response model. The inputs from a model that provides a representative simulation of measured field responses can then be used as a basis for evaluating long-term mine waste cover system performance.

Field response models attempt to recreate complexities of the real world in mathematical terms. Hence, all facets of a cover system's water balance must be addressed in the model. This includes, but is not limited to, soil-plant-atmosphere interactions, evolution (weathering) of the cover layers, and heterogeneity (as well as layering) of materials. This paper presents the current methodology used by the authors to simulate these processes. In order to illustrate the methodology, results are presented for field response models developed at three sites situated in starkly contrasting climatic regimes: an arid to semi-arid site, a humid subtropical site, and a subarctic site. The examples show that following such a methodology can result in a highly accurate set of model inputs in almost any climatic region.
\end{abstract}

\section{Introduction}

Mine waste cover systems typically represent the single largest component of a mine closure plan, not only with respect to environmental impact and cost but also public and regulatory scrutiny. Cover systems are not "one size fits all", as they must satisfy differing objectives and be exposed to different climate and vegetation conditions at each mine location. Also, cover systems are generally anticipated to be in place for perpetuity. Hence, cover system designs must be developed on a case-by-case basis using site specific cover performance criteria and with due consideration of the short and long-term impacts on the receiving environment. To this end, O'Kane and Wels (2003) put forth a rigorous procedure for cover system design, which results in the selection of a cost-effective cover system, and at the same time protects the environment. This procedure has been updated and is presented in Figure 1 and in the following information.

The process begins with site and material characterisation. Site characterisation refers to determining such elements as type of waste, size and geometry of storage facility, climate and vegetation. Material characterisation requires appraising quantities of cover and waste materials as well as (by performing field and laboratory testing) determining initial estimates of the physical properties of these materials. A conceptual cover design is then selected based on the information gathered from the site and material characterisation. Site-specific climate conditions are a key factor in developing the conceptual cover system design. A basic configuration of the conceptual design is proposed and evaluated to see if it complies with both impact and cost criteria. If the design does not comply with all criteria then it is enhanced and re-evaluated. This process is repeated until a design is found that meets all criteria or it is determined that the cover design concept is fatally flawed and needs to be re-addressed. A basic cover design passing all the criteria is then installed and monitored on a field-trial scale to ensure that it can still achieve all criteria in the real world. To aid in determining the performance of a cover design, measured field responses are simulated 
using computers by calibrating a field response model. The field response model inputs are then used as a basis to evaluate the long-term performance of a proposed cover system design.

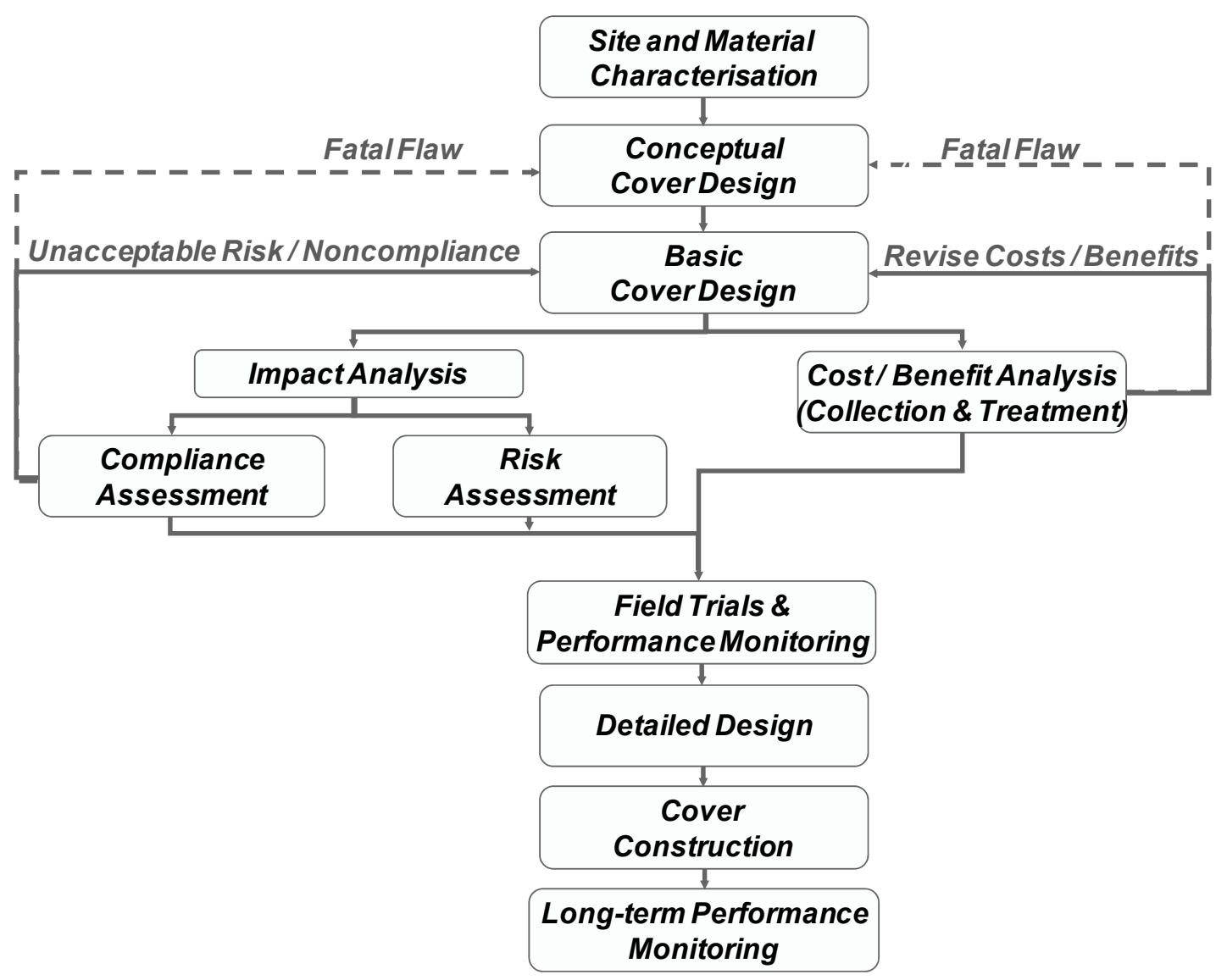

Figure 1 Flow chart of cover system design steps (adapted from O'Kane and Wels, 2003)

The development and calibration of a field response model is a complex and vital component of the cover system design process. Figure 2 provides the general steps used to calibrate a field response model with each step explained in more detail in the following sections. Examples are provided for each step illustrating the practical application of this methodology. The sites used for the examples are situated in three starkly contrasting climate regimes: an arid to semi-arid site, a humid subtropical site, and a subarctic site, showing the flexibility of the methodology and modelling program. All models were completed for this paper using the computer software VADOSE/W (Geo-Slope International, 2009).

\section{$2 \quad$ Field response model calibration methodology and examples}

\subsection{Differentiation between model calibration and model verification}

Prior to delving into the field response model calibration methodology, it is important to highlight the difference between model calibration and model verification. Model verification is testing a model by having it solve problems with known inputs and solutions to ensure that the model is programmed correctly, i.e. includes the correct (stated) set of mathematical formulations, implements algorithms properly and does not contain errors, bugs and oversights. In contrast, model calibration is the estimation of some inputs of a model, under the assumption that the model is verified, to simulate a known solution. Hence, model calibration can be viewed as model validation from a model programmer's perspective as a calibrated model confirms that the model can accurately simulate measured conditions. 


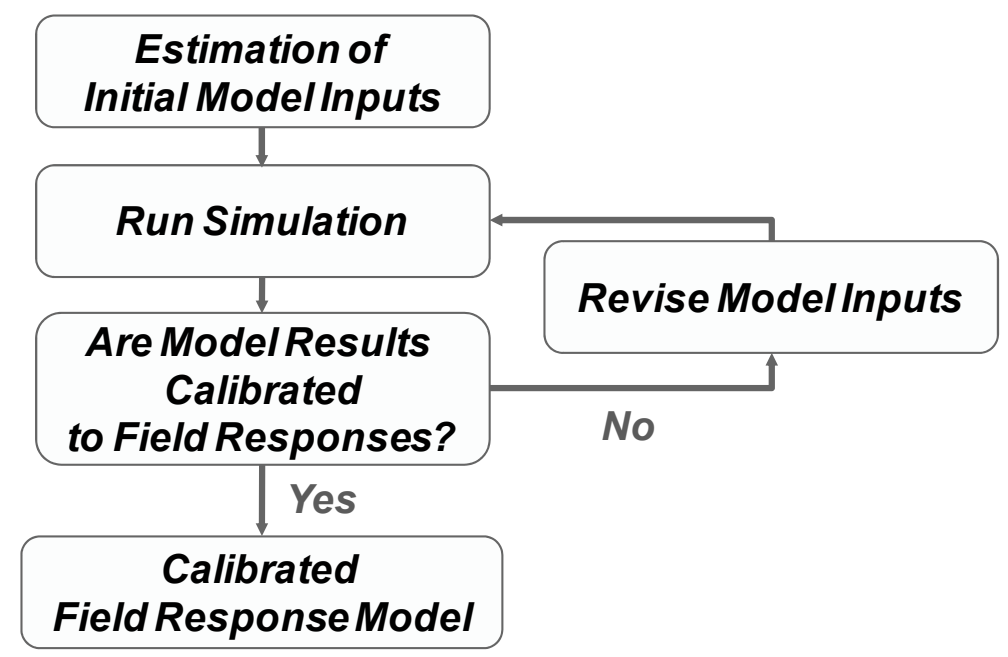

Figure 2 Flow chart of field response model calibration steps

\subsection{Estimation of initial model inputs}

The model inputs that are required for a field response model can be separated into five groups:

- Climate.

- Initial and lower boundary conditions.

- Layering.

- Material properties.

- Vegetation.

These five groups are described in more detail in the following sections.

\subsubsection{Climate}

The VADOSE/W model requires daily inputs of precipitation amount and duration, maximum and minimum temperature, maximum and minimum relative humidity, average wind speed and net radiation. All of these parameters are measured at the monitored field trial locations presented in this paper. This is extremely advantageous as it removes most of the uncertainty in these inputs. However, these inputs must still be critiqued to ensure that inaccurate measurements have not been overlooked.

The arid site provides an example of how inaccurate climate measurements can be revealed by a field response model. Figure 3 shows that the model was initially unable to accurately predict field responses for the first three months of 2003 (the rectangle on the graph) even when no runoff was allowed to leave the cover system. Hence, the precipitation inputs were compared with a secondary set of precipitation measurements taken near the field trials, which indicated the field trial precipitation measurements were incorrect for this time period. Once the secondary precipitation measurements were incorporated into the model the simulated responses were much more comparable.

\subsubsection{Initial and lower boundary conditions}

Initial conditions are defined by the field measurements on the first day of the simulation period. However, it is the authors' experience that the model needs to run for a long enough period of time so that initial conditions are not influencing model predictions. If the model is calibrated and the initial conditions reasonably defined, this period will show the model and field results converging. Any model results occurring during the convergence period should not be included in any performance analysis. 


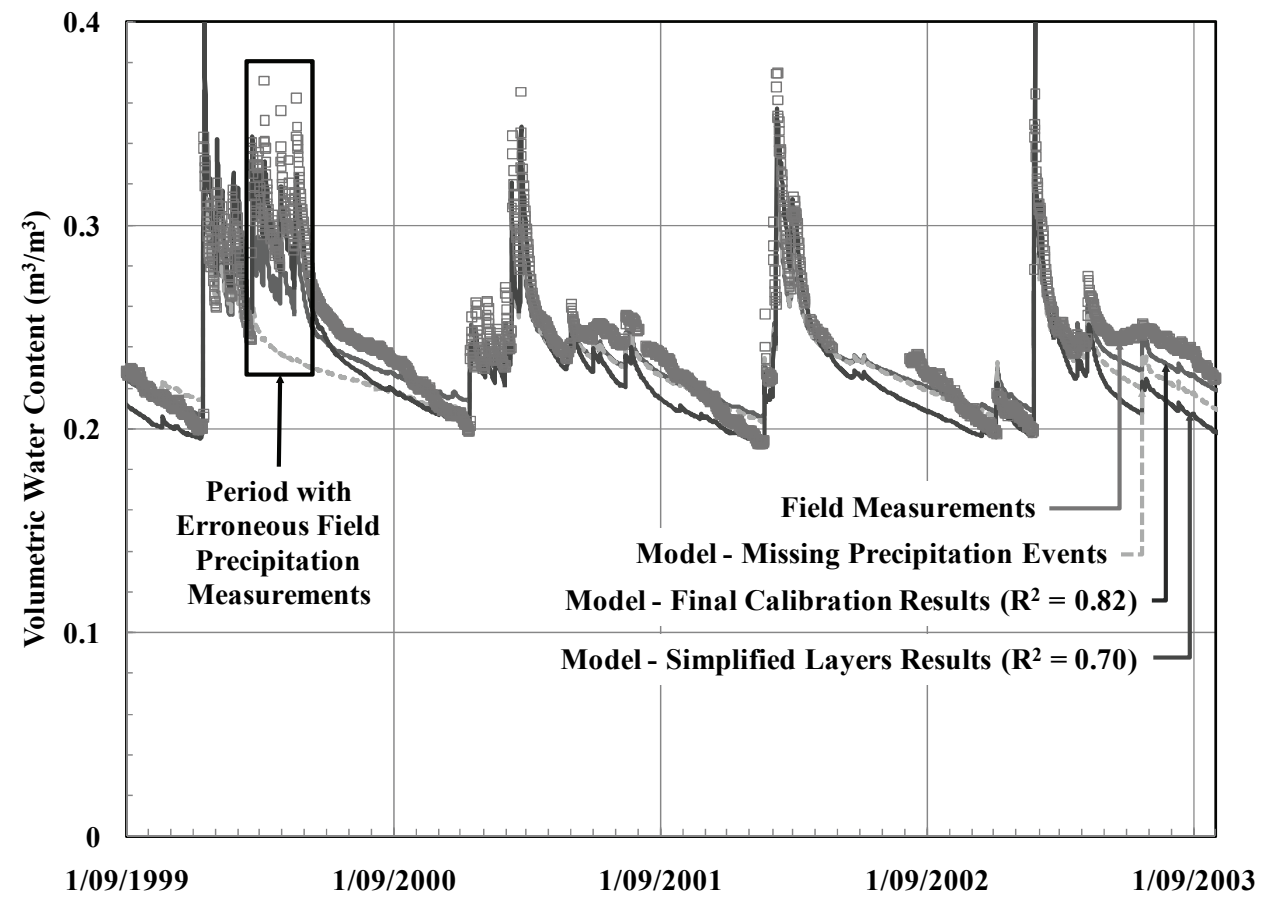

Figure 3 Measured and simulated cover water volumes for the arid site

Most cover system field response models can be adequately simulated one-dimensionally, particularly as a first pass at the modelling. Hence, side boundary conditions do not need to be defined. Exceptions exist, for example, when there is a large lateral flow component. In these cases two-dimensional models are required. However, even with a two-dimensional model, the side boundary conditions are not as important as ensuring that the side boundaries are far enough away from the area of interest that the user defined boundaries do not influence the model results.

The lower boundary of a model needs to be far enough from the monitored depth of the field trials so as to not influence the model predictions. The lower boundary is usually defined as a unit gradient unless there is a phreatic surface within close proximity to the base of the monitored field trial depth. A unit gradient boundary condition simulates the water table to be well below the base of the cover system. A unit gradient boundary condition assumes that at the lower boundary the soil suction (and, as a result, water content and hydraulic conductivity) are constant with depth. When this is the case, the total head equals the gravitational head causing a unit hydraulic gradient. In other words, a unit gradient boundary represents a location in the modelled profile where water movement is controlled primarily by gravity driven drainage at the hydraulic conductivity defined by the negative pore-water pressure (suction) condition.

\subsubsection{Layering}

In the past, field response models developed by the authors assumed that each defined layer of the waste material and cover system design is a homogeneous block of material. That is to say, that no unintentional sub-layering occurs during placement, or following a period of settlement and weathering. Sub-layering was only added when it became obvious that field conditions could not be simulated unless additional layers were added to the model. Although this process seems to follow the proper modelling procedure of starting a model as simplistic as possible and then adding complexity, it actually adds complexity to the model calibration process as it glazes over measured field material properties that can be used as known variables that usually require little or no adjustment during the calibration process. Figure 4 shows the result of such an exercise, where the material properties (in this case the hydraulic conductivity functions (k-functions)) indicate that the top $10 \mathrm{~cm}$ of the humid subtropical site must be simulated as a separate layer. 


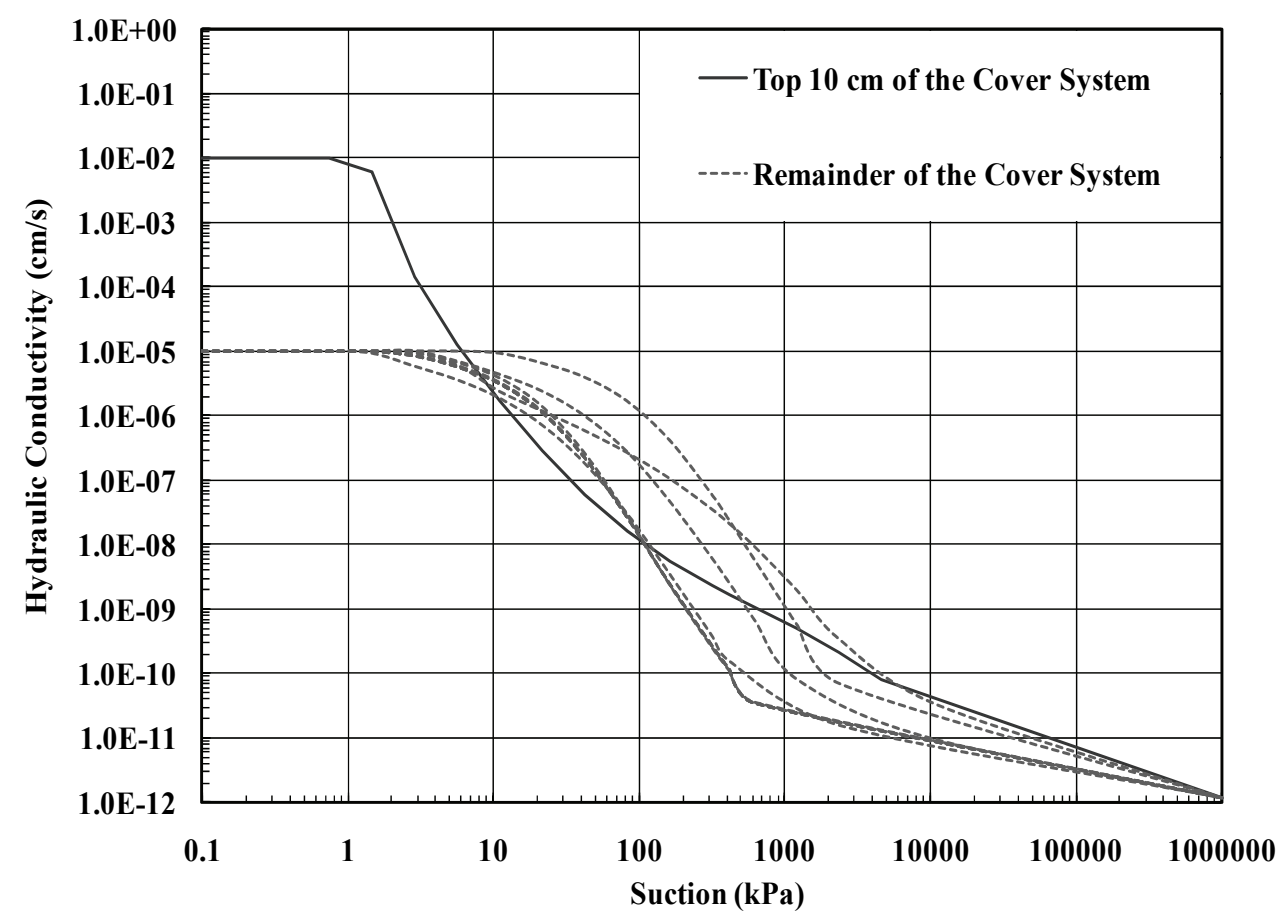

Figure 4 Range of k-functions for the humid subtropical field trial

Field response models presented in this paper use multiple sub-layers so that each sensor location in the monitored profile has a distinct set of material properties. Modelling the profiles in this way removes the subjective determination of the cover layers and provides a range of material characteristics for each soil type. Once a field response model is calibrated, the range of material characteristics can be compared to show where layers are forming within the cover and waste material profile.

\subsubsection{Material properties}

Each material layer defined in the field response model requires a unique set of material properties. The material properties required to define moisture movement within the material profile are MRC, and $\mathrm{k}$-functions. The following sections provide additional information regarding each of these properties.

Material properties evolve over time. This fact must be accounted for, particularly when simulating newly placed field trials.

\subsubsection{Moisture retention curves}

An MRC is a continuous function relating energy and the state of water, and hence describes the volumetric water content of a material as a function of soil suction, or negative pore-water pressure. Field measurements of volumetric water content and pore-water pressure measured at similar depths within a field trial are plotted together to provide an estimate of a portion of the MRC used to define each monitored depth. The porosity of a monitored location can be estimated based on field density measurements or laboratory testing. These two sections of the MRC should be considered as known initially during the field response modelling process and only be adjusted during later iterations if deemed necessary. The parts of the MRC not defined by field data (such as above $1,000 \mathrm{kPa}$ and below $10 \mathrm{kPa}$ in Figure 5) should be systematically adjusted to determine their influence on the simulated field responses. Figure 5 provides field moisture retention data for a monitored depth of the arid field trail plotted along with the estimated MRC for that depth, which was used as an input for the final calibrated arid field response model (Figure 3). 


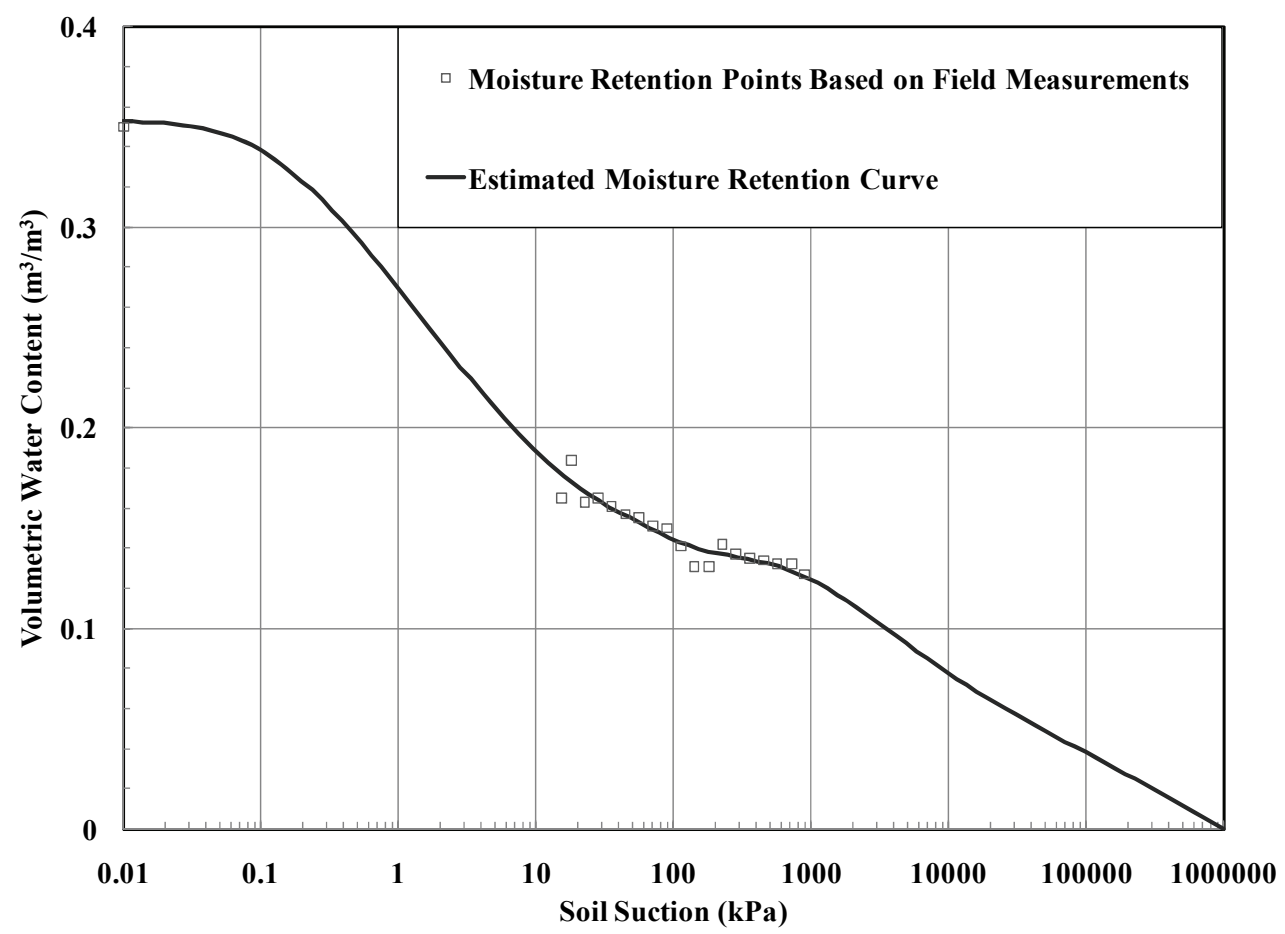

Figure 5 Typical estimated MRC for a portion of the arid field trial

The authors discourage using a closed-form solution, such as van Genuchten (1980) or Fredlund and Xing (1994), to define the MRC during initial field response model iterations. These solutions create an excellent fit for unimodal MRC, however, many materials have heterogeneous pore systems that cannot be correctly described with a unimodal MRC (Durner, 1994). To this end, Durner (1994) suggested superimposing multiple unimodal curves to define a multimodal MRC. However, even though a multimodal MRC can be defined to represent moisture retention properties for most materials, it is difficult to fine-tune such an MRC during the calibration process. Hence, the use of spline functions is recommended during the calibration process as they are more easily adjusted. A spline function is a mathematical technique to interpolate data points with curved line segments. Closed-form solutions are recommended to define MRC near the end of the calibration process if it is determined that the materials conform to a definable curve shape.

\subsubsection{Hydraulic conductivity functions}

Hydraulic conductivity is a measure of a material's ability to transmit water, and is a maximum for a saturated material. The k-function is one of the most difficult to measure. It can vary more than 10 orders of magnitude when considering soils that range from gravel to clay (Fredlund et al., 1994). As a result, prediction methods are frequently used to estimate the shape of the k-function from the more easily measured moisture retention data. Hence, initial estimates of $\mathrm{k}$-functions for field response models are usually estimated using field measurements of saturated hydraulic conductivity $\left(\mathrm{k}_{\text {sat }}\right)$ and a prediction method such as van Genuchten (1980) or Fredlund et al. (1994).

The instantaneous profile method (Richards and Weeks, 1953; Watson, 1966; Weeks and Richards, 1967; Daniel, 1983; Fredlund and Rahardjo, 1993; Eching et al., 1994) is recommended to estimate a range of unsaturated hydraulic conductivity values for a given material layer. The instantaneous profile method uses the measured changes in water content and suction to calculate the hydraulic conductivity. The resultant data points are usually disperse; leading to the initial conclusion that they are of no value. However, the instantaneous profile method data points provide a range that the estimated k-function should remain within, unless all calibration efforts prove this not to be the case. Hence, this data is compared to the function created using the chosen prediction method, and the predicted function is usually adjusted to conform to the instantaneous profile method range during subsequent iterations of the field response model. Figure 6 provides a comparison of instantaneous profile method data points to an estimated k-function for one of the arid field trial materials. 


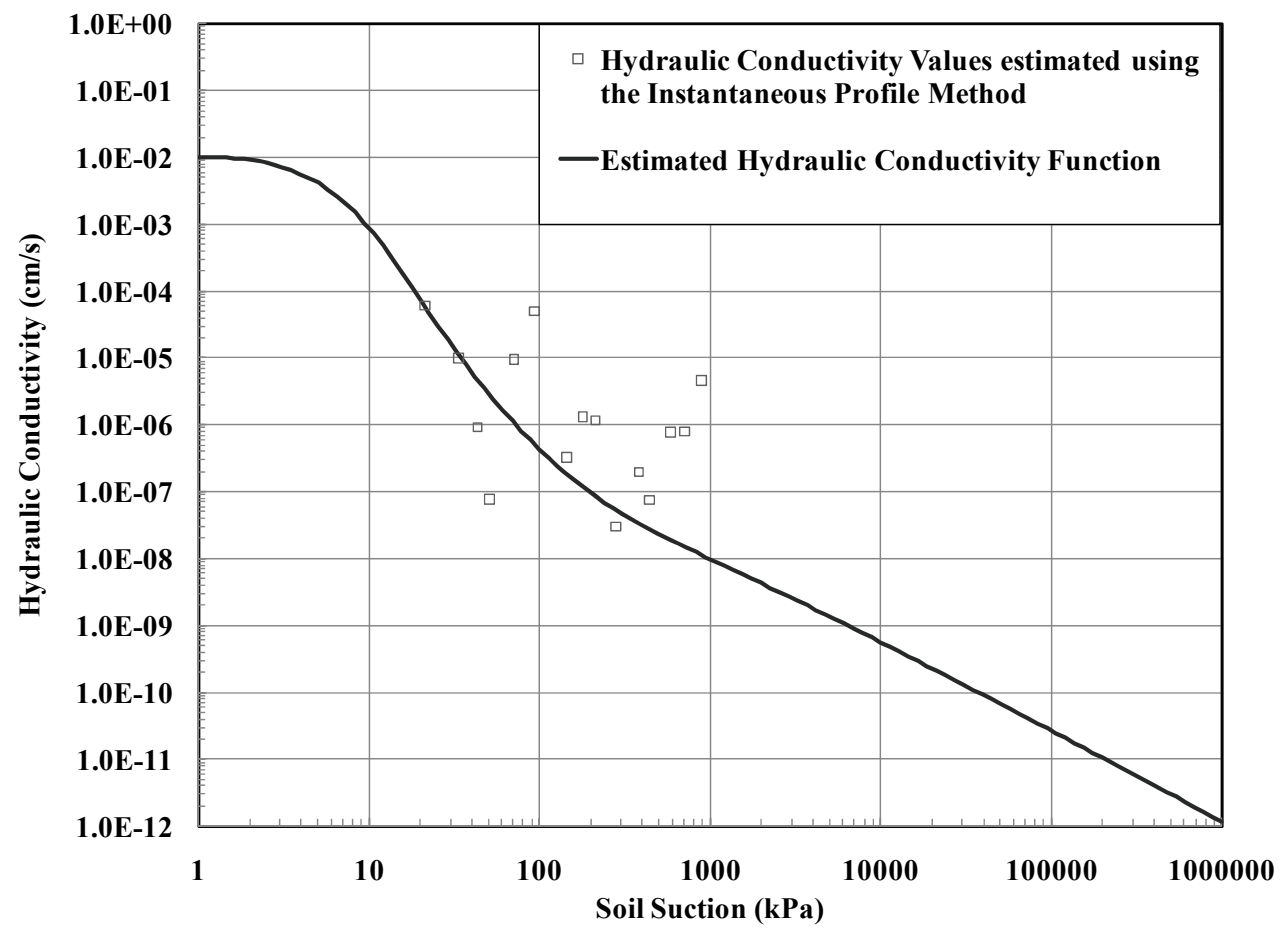

Figure 6 Typical estimated hydraulic conductivity function for a portion of the arid field trial

\subsubsection{Vegetation}

Vegetation is one of the most difficult variables to define in a field response model and also limits the certainty with which material inputs can be defined. The question often comes up during the field response modelling calibration process, "Are the field responses being observed due to vegetation or material properties?". Hence, it is advisable to initially calibrate the model to time periods when the influence of vegetation is minimal, i.e. before and after the growing season or prior to the establishment of vegetation on the field trials, so that material properties can be quickly adjusted without the need to address the aforementioned question. Once these non-vegetated time periods have been sufficiently calibrated the field response models can be completed including the growing seasons. However, the first iteration of the model with the inclusion of the growing seasons should be completed without vegetation simulated to aid in determining when the growing seasons begin and end based on a comparison of measured and simulated responses. The vegetation can then be added and adjusted during subsequent iterations.

The dominant plant species growing on the field trials, specifically above the monitored locations, must be observed as part of the field trials monitoring programme and, ideally, the life cycles of the species documented. Test pits may also be dug to determine the rooting depth and root mass distribution. Each dominant plant species must be researched to determine:

- Factors that result in germination (for an annual or newly establishing species) and/or resumption of growth.

- Anticipated rooting depth and root distribution.

- Factors that result in plant dormancy and/or the end of the growing season.

The field observations and research provide general guidelines for defining plant growth in the model. However, these guidelines can rarely be considered as known variables. The best example of this is rooting depth. Field measurements and research may both show that roots penetrate the full thickness of a given cover, but the model results often indicate that water is only removed from a portion of the rooting depth. This is consistent with Eamus et al. (2006) who found that plants preferentially extract water where plant density is highest, and can only extract small quantities of water where root density is low (Eamus et al., 2006). Hence, Eamus et al. (2006) noted that the maximum depth to which root development extends should not be considered as being the depth to which water will be extracted from a soil profile. 
The importance of simulating vegetation is shown in Figure 7. When the subarctic field trail is simulated without vegetation inputs the model underestimates the rate of water removal from the cover. When vegetation is included in the model, results more closely predict field responses.

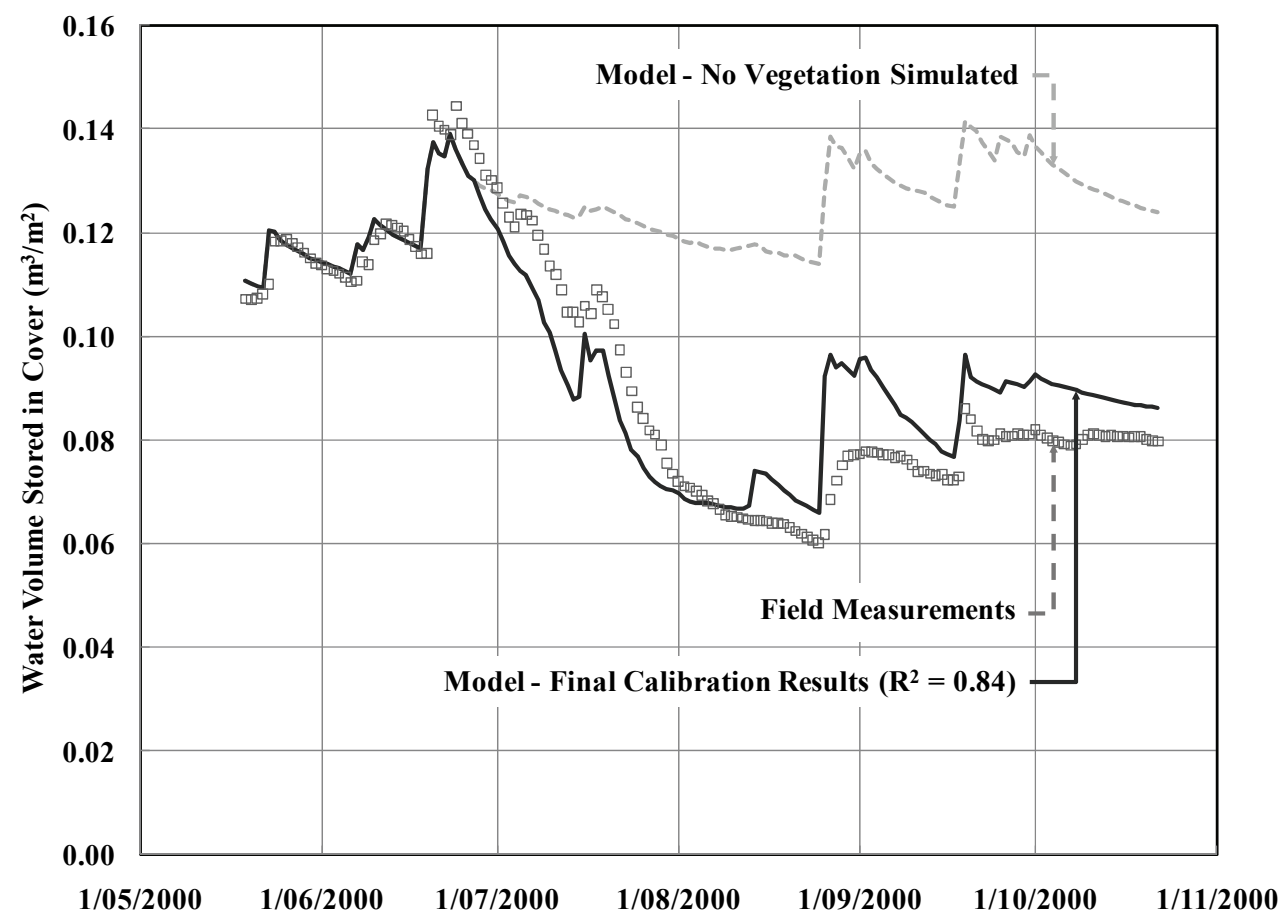

Figure 7 Measured and simulated cover water volumes for the subarctic site

\subsection{Running the simulation}

Field response models are relatively short in duration, with most simulating less than 10 years of measured field responses. Hence, model run times are rarely prohibitive for completing a field response model. Therefore, model convergence criteria (such as time steps) can be minimised and model results can be output more frequently.

The authors contend that model results should be output at least as often as the field measurements being compared as there may be a lag between field and model responses.

\subsection{Model iterations and revising model inputs}

Field response models require many iterations before they can be considered calibrated and able to reasonably estimate field responses. Reducing the number of iterations is achieved by systematically adjusting the model and only adding complexity when deemed absolutely necessary. Hence, as described in Section 2.2.5, initial iterations should be simulated without vegetation until a point is reached where additional adjustments to the material properties do not improve the model results or are considered unreasonable.

If a model seems to be predicting too much runoff, first simulate the system with no runoff to see if the result is beneficial. If the result is beneficial, systematically adjust the material properties until the proper amount of runoff is generated. If the result is not beneficial it may be an indication that climate conditions are incorrect (as shown previously in Figure 3).

It is crucial that one resists the urge to make too many changes to the model at one time. Each change should be easily defined and documented so that its impact on results can be determined. 


\subsection{Calibrated field response model}

No field response model can be calibrated to perfectly predict all field responses. Furthermore, it must be kept in mind that there is no single unique calibration. Not every nuance of the soil-plant-atmosphere flow regime can be (or likely will ever be) accounted for and different models may lead to equally acceptable representations of field responses; a condition referred to as equifinality (Beven and Binley, 1992; Beven and Freer, 2001; Beven, 2006). Hence, at some point, no additional changes will enhance the model predictions. At this point the model can be considered reasonably calibrated and its inputs can be used as a basis for evaluating long-term mine waste cover system performance. This being said, comprehensive testing of the potential range of input parameters (alone and in concert) must be undertaken to determine how sensitive (or insensitive) the model is to changes in each model input. The calibrated model should also be completed and compared to measurements at multiple monitored locations on a cover system to enhance understanding with regards to spatial variations in cover performance. As written by Ebel and Loague (2006), “...the equifinality problem becomes tractable when both integrated and distributed response data are used to assess model performance".

Figures 3 and 7 provide results of calibrated models for the arid and subarctic sites, respectively. Both these sites had sufficient field moisture retention measurements so that a comparison of field and simulated cover water volumes was possible. However, the humid subtropical site has limited moisture retention data, limiting the effectiveness of such a comparison. There are however many field responses that a model can be compared with to determine if it is accurately predicting field conditions. Two examples are provided in Figures 8 and 9. Figure 8 shows that the humid subtropical model can accurately predict field actual evapotranspiration measurements. Figure 9 shows that the humid subtropical model is also able to accurately predict changes in soil suction at the deepest monitored location for the field trial $(1.5 \mathrm{~m})$. As described in Section 2.2.2, it takes time for the model to overcome the user defined initial conditions. This is shown in Figure 9 where it takes the model approximately 30 days to converge to field measurements. After this point the initial model conditions input by the user are not influencing model results.

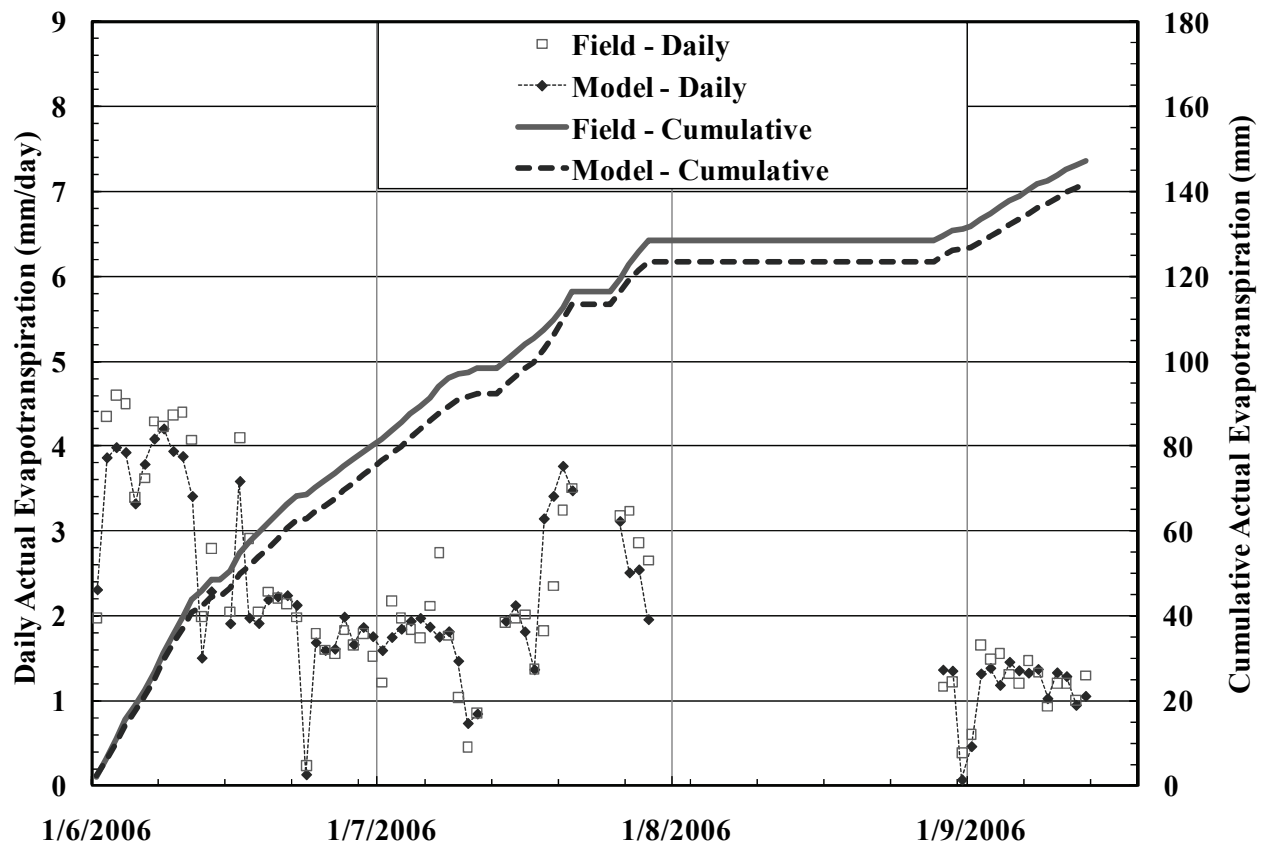

Figure 8 Measured and simulated actual evapotranspiration for the humid subtropical site

\section{$3 \quad$ Application of field response models}

Once a field response model has been calibrated its inputs can be used as a basis for a series of long-term models evaluating different long-term scenarios to aid in engineering judgement. However, the authors recommend that that the calibrated model first be simplified by grouping layers with similar material properties, such as the example presented in Figure 4. The field response model should then be completed 
one more time to ensure that the simplified layering still reasonably predicts field conditions (such as the "Simplified Layers Results" shown in Figure 3) and that the simulated site water balance, such as the one for the humid subtropical site shown in Figure 10, conforms with site knowledge.

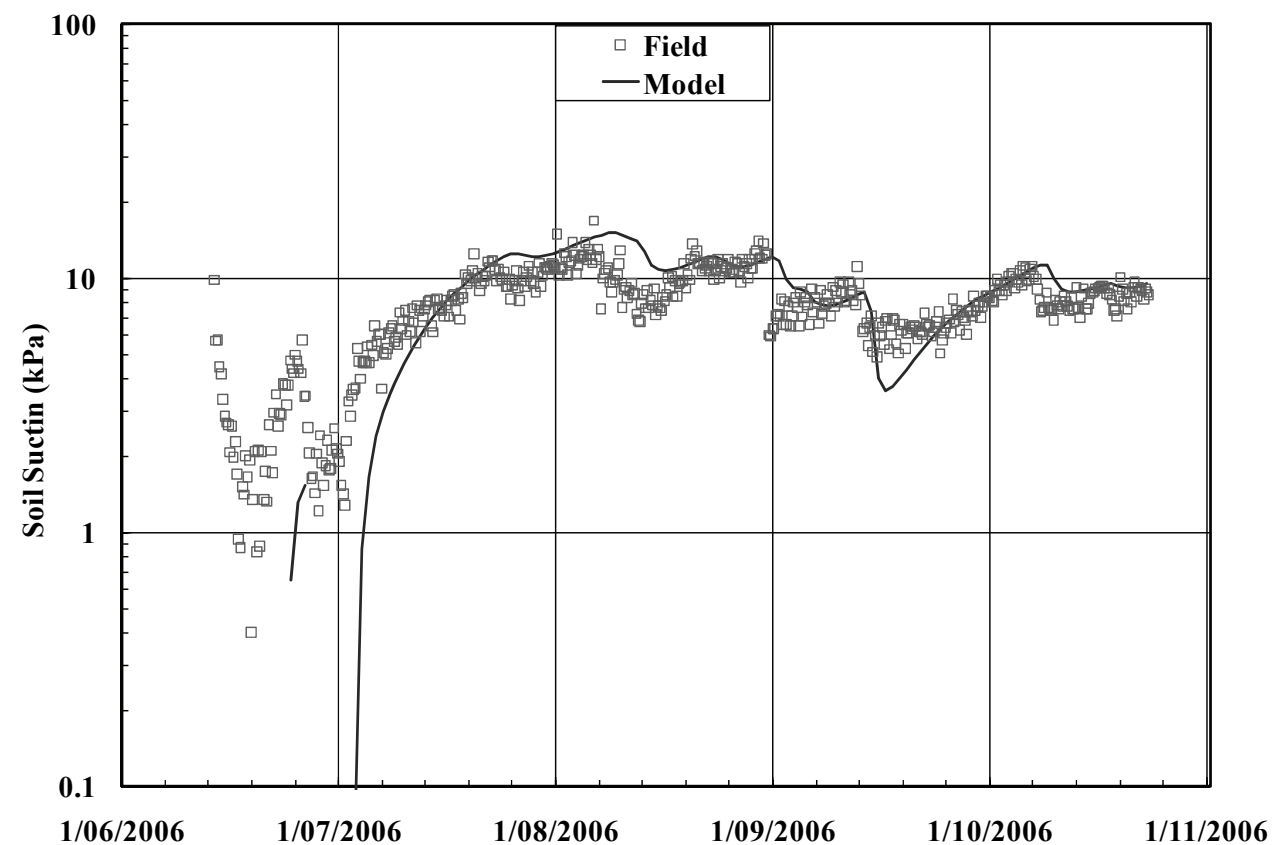

Figure 9 Measured and simulated actual evapotranspiration for the humid subtropical site

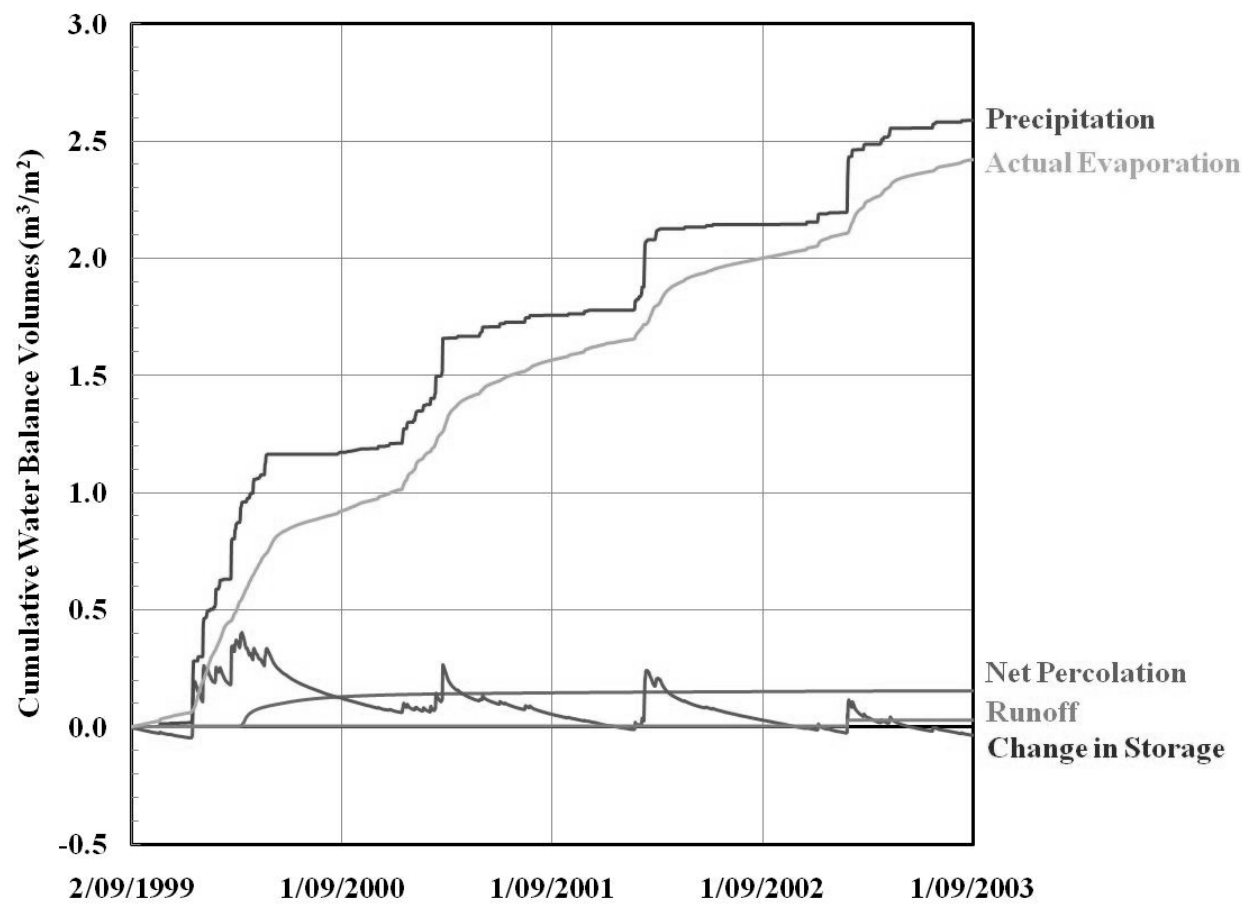

Figure 10 Simulated water balance at the humid subtropical site

Simplifying the model in this way makes it easier for model users and reviewers to test general performance of the cover system and analyse results. It also makes it clear for any lay person reviewing the model that the additional layering does not need to be consciously included in the cover system design.

Long-term models completed using inputs developed from field response models allow users to estimate long-term cover performance and evaluate how changes to materials, climate and vegetation will impact 
long-term performance. Figure 11 provides an example of such simulations, showing the estimated water table depth for 100 years at the humid subtropical site for a variety of possible site conditions.

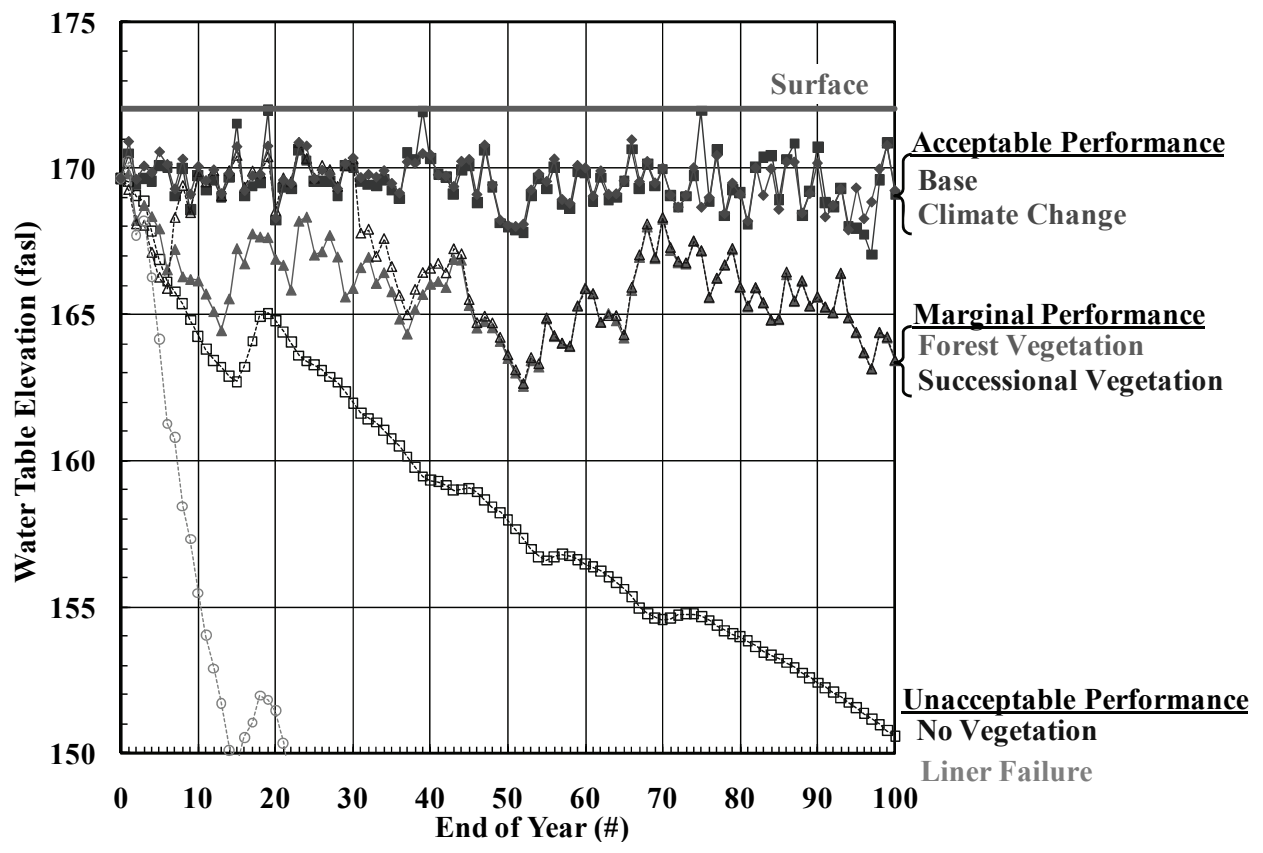

Figure 11 Simulated long-term cover system performance at the humid subtropical site

\section{Summary}

Field response modelling is the most appropriate method of determining and validating a set of model inputs for a mine waste cover system. However, field response modelling requires the accurate prediction of complex soil-plant-atmosphere interaction with time. Hence, the modelling process requires many iterations before accurate estimates of field responses can be realised. The changes to the model made between iterations must be deliberate and documented to limit the number of iterations required to obtain calibration.

This paper presents a methodology for cover system field response modelling that can be used to develop a calibrated field response model. The methodology is discussed, and examples of the application of the methodology are provided to illustrate the process. Application of this, or a similar methodology, is fundamental in developing a model that can be used as a basis for evaluating long-term cover system performance under a variety of conditions.

\section{References}

Beven, K.J. and Binley, A.M. (1992) The future of distributed models; model calibration and uncertainty prediction, Hydrological Processes, Vol. 6, pp. 279-298.

Beven, K.J. and Freer, J. (2001) Equifinality, data assimilation, and uncertainty estimation in mechanistic modelling of complex environmental systems, Journal of Hydrology, Vol. 249, pp. 11-29.

Beven, K.J. (2006) A manifesto for the equifinality thesis, Journal of Hydrology, Vol. 320, pp. 18-36.

Daniel, D.E. (1983) Permeability Test for Unsaturated Soil, Geotechnical Testing Journal, Vol. 6, No. 2, pp. 81-86.

Durner, W. (1994) Hydraulic conductivity estimation for soils with heterogeneous pore structure, Water Resources Research, Vol. 30, No. 2, pp. 211-223.

Eamus, D., Hatton, T., Cook, P. and Colvin, C. (2006) Ecohydrology, Vegetation Function, Water and Resource Management, CSIRO Publishing.

Ebel, B.A. and Loague, K. (2006) Physics-based hydrologic-response simulation: Seeing through the fog of equifinality, Hydrological Processes, Vol. 20, pp. 2887-2900.

Eching, S.O., Hopmans, J.W. and Wendroth, O. (1994) Unsaturated Hydraulic Conductivity from Transient Multistep Outflow and Soil Water Pressure Data, Soil Science Society of America Journal, Vol. 58, pp. 687-695.

Fredlund, D.G. and Rahardjo, H. (1993) Soil Mechanics for Unsaturated Soils, John Wiley and Sons Inc., New York.

Fredlund, D.G. and Xing, A. (1994) Equations for the Soil-Water Characteristic Curve, Canadian Geotechnical Journal, Vol. 31, pp. 521-532. 
Fredlund, D.G., Xing, A. and Huang, S. (1994) Predicting the permeability function for unsaturated soils using the soilwater characteristic curve, Canadian Geotechnical Journal, Vol. 31, pp. 533-546.

Geo-Slope International Ltd (2009) GeoStudio 2007, viewed 27 April 2009, http://www.geo-slope.com/.

O'Kane, M. and Wels, C. (2003) Mine Waste Cover System Design - Linking Predicted Performance to Groundwater and Surface Water Impacts, Sixth International Conference on Acid-Rock Drainage, Cairns, Australia, July.

Richards, S.J. and Weeks, L.V. (1953) Capillary Conductivity Values from Moisture Yield and Tension Measurements in Soil Columns, Soil Science Society of America Proceedings, Vol. 17, No. 3, pp. 206-209.

van Genuchten, M.T. (1980) A Closed-form Equation for Predicting the Hydraulic Conductivity of Unsaturated Soils, Soil Science Society of America Journal, Vol. 44, No. 5, pp. 892-898.

Watson, K.K. (1966) An Instantaneous Profile Method for Determining the Hydraulic Conductivity of Unsaturated Porous Materials, Water Resources Research, Vol. 2, No. 4, pp. 709-715.

Weeks, L.V. and Richards, S.J. (1967) Soil-Water Properties Computed from Transient Flow Data, Soil Science Society of America Proceedings, Vol. 31, No. 6, pp. 721-725. 